\title{
LOW TEMPERATURE BONDING FOR FABRICATION OF MINIATURIZED CHEMICAL ANALYSIS DEVICES
}

\author{
HongYing Wang, Robert S. Foote, Stephen C. Jacobson and J. Michael Ramsey \\ Chemical \& Analytical Sciences Division, Oak Ridge National Laboratory \\ P.O. Box 2008, Oak Ridge, TN 37831-6142
}

\begin{abstract}
A low temperature bonding process was developed for the fabrication of microchip devices for liquid phase chemical analysis. Photolithographically etched microchannels on glass substrates were closed by bonding a glass cover plate using sodium silicate as an adhesive. Good channel sealing was achieved at $90^{\circ} \mathrm{C}$ for an hour. The performance of the device was evaluated by monitoring the electroosmotic flow on the chip. The strength of the bonding was studied using electrical and mechanical methods. The results were compared with that obtained from the device made from high temperature glassglass direct bonding.
\end{abstract}

\section{INTRODUCTION}

Microfabricated miniature instruments for complete chemical analysis are receiving increased attention. Various microdevices have been fabricated that perform liquid phase analysis including capillary electrophoresis [1-3], electrochromatography [4], micellar electrokinetic capillary chromatography [5], DNA restriction fragment analysis [6-7], and on-chip chemical reactions with analysis [8]. The devices were fabricated by etching the channel manifolds into glass substrates using standard photolithographic and wet chemical etching methods. The first devices reported used a melting technique to bond the substrate and cover plate at $620^{\circ} \mathrm{C}$ to form a network of closed channels [1]. A direct bonding technique was also developed by which the substrate and cover plate were joined and then annealed at $500^{\circ} \mathrm{C}$ [3]. However, the high temperature bonding process hindered the further device fabrication, such as immobilizing biological species in the channel, or integration of structural features (e.g. electrodes, waveguides etc.) into the channel. A low temperature bonding process has been reported to bond silicon wafers at $200-300{ }^{\circ} \mathrm{C}$ using sodium silicate as a bonding layer [9]. Here, we report a modified process to perform glass-glass bonding using sodium silicate at the process temperature lower than $100^{\circ} \mathrm{C}$.

\section{EXPERIMENTAL}

Standard $50 \mathrm{~mm} \times 25 \mathrm{~mm}$ glass microscope slide and 22 $\mathrm{mm}$ circular or $25 \mathrm{~mm} \times 25 \mathrm{~mm}$ square coverslip were used for the bonding experiments. The substrate and the coverslip were treated as follows: (i) Hydrolyze in $\mathrm{NH}_{4} \mathrm{OH} / \mathrm{H}_{2} \mathrm{O}_{2} / \mathrm{H}_{2} \mathrm{O}(2: 1: 3)$ solution at $60{ }^{\circ} \mathrm{C}$ for $20 \mathrm{~min}$. (ii) Spin-on a dilute solution of sodium silicate in water on the coverslip at $4000 \mathrm{rpm}$ for 10 seconds. (iii) Immediately bring the coverslip in contact with the glass substrate. (iv) Anneal the sample at $90^{\circ} \mathrm{C}$ for 1 hour.

The electroosmotic flow was studied on the chip using Rhodamine $B$ as a probe and laser induced fluorescence. The schematic for the measurement of electrical breakdown of the bonding is shown in Fig. 1 with a separation of $150 \mu \mathrm{m}$ between the two channels. The specimens for the mechanical strength measurement were prepared by etching a glass slide to form a

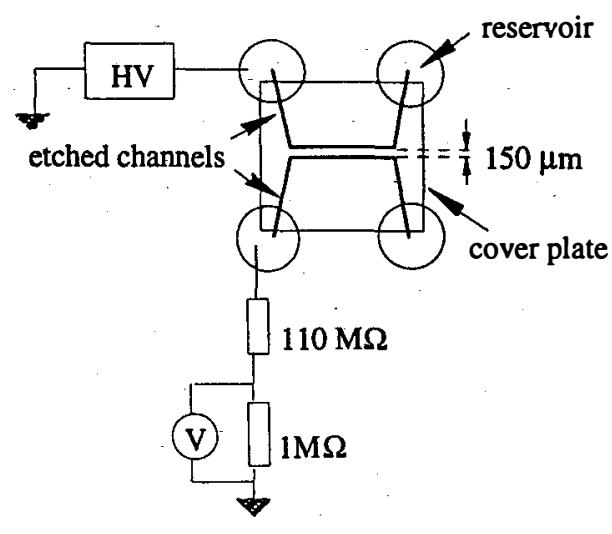

Figure 1. Schematic for the measurement of dielectric strength between microfabricated channels.

triangular area $4 \mu \mathrm{m}$ above the glass surface and bonding another piece of glass slide on the triangular area. The measurements were done on an Instron 4501 machine and the surface energy was obtained by integrating the area under the load vs. displacement curves [10].

\section{RESULTS AND DISCUSSION}

The electroosmotic flow measurements with the chip made using the low temperature bonding method are shown in Fig. 2. The measurements were done after flushing the chip with water or $1 \mathrm{~N} \mathrm{NaOH}$. The $\mathrm{NaOH}$ flush regenerates the hydrophilic glass surface and enhances the electroosmotic flow. The results compare well with that obtained from chips made using the high temperature direct bonding method.

Figure 3 shows the electrical breakdown data for the chip

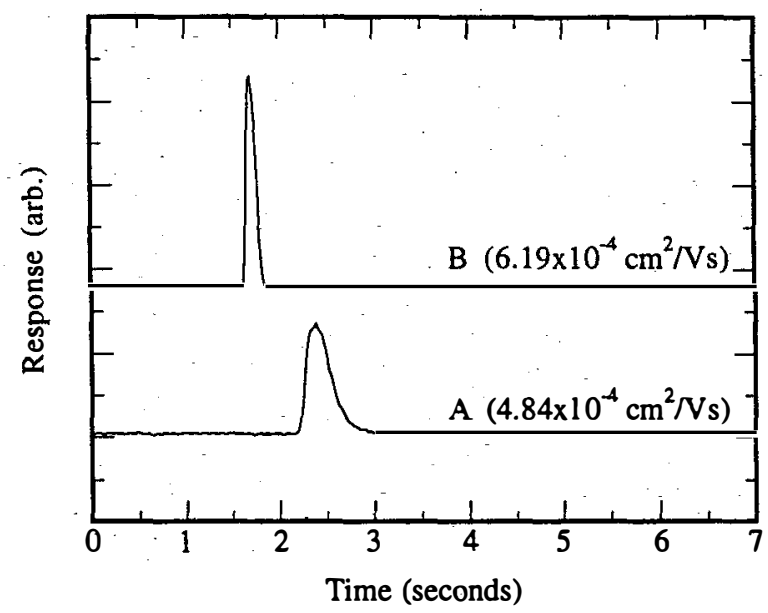

Figure 2. Electroosmotic flow for chips made using the low temperature bonding method: (A) flush with water for 20 mins, (B) flush with IN NaOH for 20 mins. 
bonded with 2 wt.\% sodium silicate. The data was used to determine the dielectric strength of the bonding layer. The breakdown occurred at the applied voltage of $6 \mathrm{kV}$, which corresponds to a dielectric strength of $400 \mathrm{kV} / \mathrm{cm}$. The breakdown was irreversible since a current path was formed after the breakdown, which is believed to be due to the sodium ions in the sodium silicate bonding layer. Compared with the low temperature bonding, the high temperature direct bonding is much stronger with a dielectric strength of $1100 \mathrm{kV} / \mathrm{cm}$, as shown in Fig.4. The breakdown was reversible, as can be seen in Fig. 4 in that it "healed" after the applied voltage was reduced. This may be attributed to the fact that the breakdown was caused by the movement of the electrons relative to their nuclei to constitute a displacement current [11]. Therefore the breakdown current of the high temperature bonding is much lower than that of the low temperature bonding.

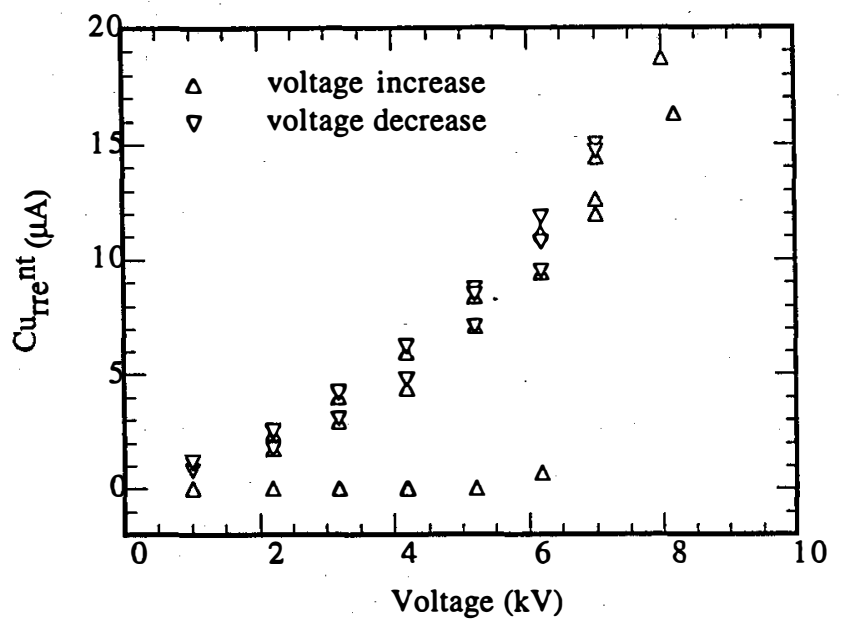

Figure 3. Electrical breakdown measurement of the chip made using the low temperature bonding method.

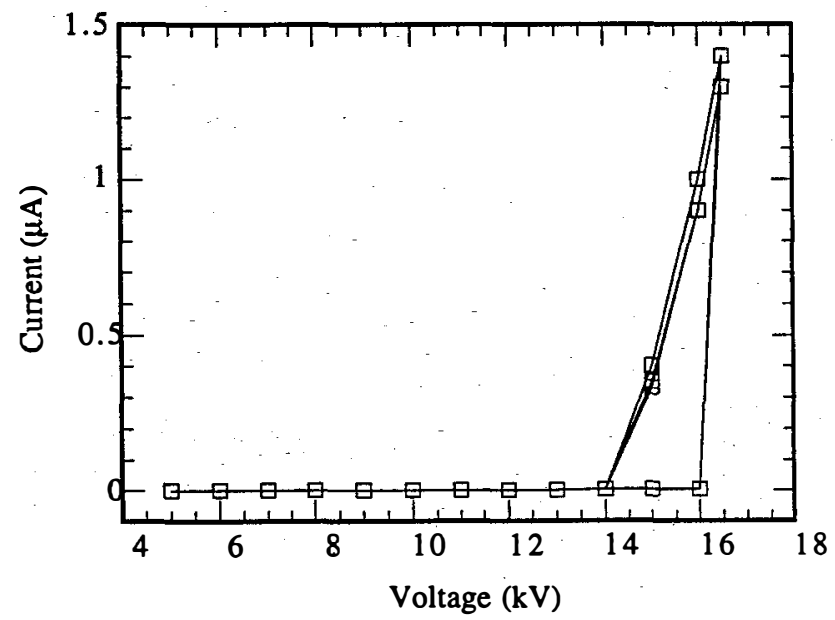

Figure 4. Electrical breakdown measurement of the chip made using the high temperature direct bonding method.

The surface energy obtained from the mechanical strength measurements for the sodium silicate bonding $\left(2 \mathrm{wt} . \%\right.$ at $90^{\circ} \mathrm{C}$ ) is around $2.6 \mathrm{~J} / \mathrm{m}^{2}$, which is comparable to the value of $2.2 \mathrm{~J} / \mathrm{m}^{2}$ obtained in conventional wet oxidized silicon direct bonding at $1400{ }^{\circ} \mathrm{C}$ [12], and also is comparable to the value of $3 \mathrm{~J} / \mathrm{m}^{2}$ obtained in the low temperature silicon wafer bonding with sodium silicate at $>200{ }^{\circ} \mathrm{C}$ [9]. The high temperature direct bonding gives a surface energy of around $6.7 \mathrm{~J} / \mathrm{m}^{2}$ which is close to the virgin glass fracture energy [13].

\section{CONCLUSION}

The low temperature bonding process has provided strong bonds between glass surfaces and good channel sealing for liquid phase analysis. Further applications in fabricating various devices for chemical and biological analysis are under investigation.

\section{ACKNOWLEDGEMENTS}

This research is sponsored by Oak Ridge National Lab (ORNL). ORNL is managed by Lockheed Martin Energy Systems, Inc. for the U.S. Department of Energy under contract DE-AC05-96OR22464. Also, this research is sponsored in part by an appointment for H.W. to the ORNL Postdoctoral Research Associates Program administered by the Oak Ridge Institute for Science and Education and ORNL.

\section{REFERENCES}

1. D.J. Harrison, A. Manz, Z. Fan, H. Lüdi, and H.M. Widmer, "Capillary Electrophoresis and Sample Injection Systems Integrated on a Planar Glass Chip", Anal. Chem., 64, 1926 (1992).

2. A. Manz, D.J. Harrison, E. Verpoorte, J.C. Fettinger, A. Paulus, H. Lüdi, and H.M. Widmer; "Planar Chips Technology for Miniaturization and Integration of Separation Techniques into Monitoring Systems. Capillary Electrophoresis on a Chip", J. Chromatogr. 593, 253 (1992).

3. S.C. Jacobson, R. Hergenröder, L.B. Kourny, R.J. Warmack, and J.M. Ramsey, "Effects of Injection Schemes and Column Geometry on the Performance of Microchip Electrophoresis Devices", Anal. Chem., 66, 1107 (1994).

4. S.C. Jacobson, R. Hergenröder, L.B. Koutny, and J.M. Ramsey, "Open Channel Electrochromatography on a Microchip”, Anal. Chem., 66, 2369 (1994).

5. A.W. Moore, Jr., S.C. Jacobson, and J.M. Ramsey, "Microchip Separations of Neutral Species via Micellar Electrokinetic Capillary Chromatography", Anal. Chem., 67, 4184 (1995).

6. A.T. Woolley and R.A. Mathies, "Ultra-High-Speed DNA Fragments Separations Using Microfabricated Capillary Array Electrophoresis Chips", Anal. Chem., 67, 3676 (1995).

7. S.C. Jacobson and J.M. Ramsey, "Integrated Microdevices for DNA Restriction Fragment Analysis", Anal. Chem., 68, 720 (1996).

8. S.C. Jacobson, R. Hergenröder, A.W. Moore, Jr., and J.M. Ramsey, "Precolumn Reactions with Electrophoretic Analysis Integrated on a Microchip", Anal. Chem., 66, 4127 (1994).

9. H.J. Quenzer and W. Benecke, "Low-Temperature Silicon Wafer Bonding", Sensors and Actuators A, 32 , 340 (1992).

10. J.H. Schneibel and M.G. Jenkins, "Slow Crack Growth at Room Temperature in FeAl", Scripta Metallurgica et Materialia, 28, 389 (1993).

11. L. Holland, "The Properties of Glass Surfaces", John Wiley \& Sons Inc., New York, 1964, Chapter 9, p456.

12. W.P. Maszara, "Silicon-on-Insulator by Wafer Bonding: A Review", J. Electrochem. Soc., 138, 341_(1991).

13. R.W. Davidge and G. Tappin, "The Effective Surface Energy of Brittle Materials”, J. Mater. Sci., 3, 165 (1968). 